\title{
Some aspects of the energy balance closure problem
}

\author{
T. Foken, F. Wimmer, M. Mauder, C. Thomas, and C. Liebethal \\ Department of Micrometeorology, University of Bayreuth, 95440 Bayreuth, Germany \\ Received: 23 November 2005 - Published in Atmos. Chem. Phys. Discuss.: 27 April 2006 \\ Revised: 20 July 2006 - Accepted: 21 September 2006 - Published: 28 September 2006
}

\begin{abstract}
After briefly discussing several reasons for the energy balance closure problem in the surface layer, the paper focuses on the influence of the low frequency part of the turbulence spectrum on the residual. Changes in the turbulent fluxes in this part of the turbulence spectrum were found to have a significant influence on the changes of the residual. Using the ogive method, it was found that the eddy-covariance method underestimates turbulent fluxes in the case of ogives converging for measuring times longer than the typical averaging interval of $30 \mathrm{~min}$. Additionally, the eddy-covariance method underestimates turbulent fluxes for maximal ogive functions within the averaging interval, both mainly due to advection and non-steady state conditions. This has a considerable influence on the use of the eddy-covariance method.
\end{abstract}

\section{Introduction}

During the late 1980s it became obvious that the energy balance at the earth's surface could not be closed with experimental data. The available energy, i.e. the sum of the net radiation and the ground heat flux, was found in most cases to be larger than the sum of the turbulent fluxes of sensible and latent heat. This was a main topic of a workshop held in 1994 in Grenoble (Foken and Oncley, 1995). In most of the land surface experiments (Bolle et al., 1993; Kanemasu et al., 1992; Tsvang et al., 1991), and also in the carbon dioxide flux networks (Aubinet et al., 2000; Wilson et al., 2002), a closure of the energy balance of approximately $80 \%$ was found. The residual is

Res $=R_{n}-H-\lambda E-G$

with $R_{n}$ : net radiation, $H$ : sensible heat flux, $\lambda E$ : latent heat flux, and $G$ : soil heat flux. The problem cannot be described

Correspondence to: T. Foken

(thomas.foken@uni-bayreuth.de) only as an effect of statistically distributed measuring errors because of the clear underestimation of turbulent fluxes or overestimation of the available energy. In the literature, several reasons for this incongruity have been discussed, most recently in an overview paper by Culf et al. (2004):

i) The most common point of discussion were measurement errors, especially those of the eddy-covariance technique, which cause a systematic underestimation of the turbulent fluxes. Improvements in the sensors, in the correction methods and the application of a more stringent determination of the data quality (Foken et al., 2004) have made this method much more reliable in the past ten years (Moncrieff, 2004).

ii) Because of different balance layers and scales of diverse measuring methods (net radiation - surface, turbulent fluxes - approx. $5 \mathrm{~m}$ above the surface, and soil heat flux - approx. $10 \mathrm{~cm}$ below the surface), the energy storage in the canopy and the soil was often discussed as a reason for the unclosed energy balance. Foken et al. (2001) reported for the total solar eclipse over Europe in 1999 that there is a time shift between the irradiation and the turbulent fluxes of up to $30 \mathrm{~min}$, which has an influence on the energy balance closure. Kukharets et al. (2000) also found that the soil heat flux and the energy balance closure are closely related due to the energy storage in the upper soil layer. For an exact determination of the soil heat flux, including storage effects, the energy balance was shown to be closed at night for non-turbulent conditions (Mauder et al., 2006). The storage in the canopy is often negligible.

iii) The unclosure of the energy balance was also connected with the heterogeneity of the land surface (Panin et al., 1998). The authors assumed that the heterogeneities generate eddies at larger time scales than eddies measured with the eddy-covariance method. This problem

Published by Copernicus GmbH on behalf of the European Geosciences Union. 
is also closely connected with advection and fluxes due to longer wavelengths (Finnigan et al., 2003; Sakai et al., 2001) or organized turbulence structures (Inagaki et al., 2006; Kanda et al., 2004).

This study is based on a selected data set of the LITFASS2003 experiment (Mengelkamp et al., 2006) and focuses on the last question (iii) of the closure problem. It is assumed that the problems related to questions (i) and (ii) were verified and corrected according to our present knowledge for the data set used by Mauder et al. (2006). The present study investigates single time series for a selected data set instead of the presentation of daily cycles and sums of the residual of the energy balance closure as done by Mauder et al. (2006) for the LITFASS-2003 experiment.

\section{Selected data set of the LITFASS-2003 experiment}

The aim of the LITFASS-2003 experiment in May and June of 2003 was to investigate turbulent fluxes in an heterogeneous landscape sized as a typical numerical weather and climate model of $20 \times 20 \mathrm{~km}^{2}$ (Beyrich et al., 2002a) in the region of the Meteorological Observatory Lindenberg of the German Meteorological Service southeast of Berlin, Germany. The experimental design was similar to the earlier experiment LITFASS-98 (Beyrich et al., 2002b) with an updated und enlarged measuring concept and closer relations to the modelling concept. For this study, only the data set of the University of Bayreuth over a maize field (Zéa máys L.) was selected. It was located near the Boundary-Layer Field Site of the German Meteorological Service $\left(52^{\circ} 10^{\prime} 01^{\prime \prime} \mathrm{N}\right.$, $14^{\circ} 07^{\prime} 27^{\prime \prime} \mathrm{E}, 73 \mathrm{~m}$ a.s.1.) at Falkenberg. The field can be characterized as nearly bare soil at the beginning of the experiment and by a canopy height of about $45-55 \mathrm{~cm}$ on the selected days of this study with a very low leaf-area index.

For this investigation, a data set of only three days (0709/06/2003) was selected, which was characterised by an increasing wind velocity from 07 to $09 / 06 / 2003$ and nearly ideal and identical daily cycles of irradiation with only some scatter due to clouds on 09/06/2003. The conditions discussed later are not restricted to this period; the selected days are "Golden Days" to explain these results of this study. The results are also compared with the data set of the whole experiment from 22/05/2003 to 17/06/2003.

Furthermore, the site was intentionally selected to make use of high quality sensors and the opportunity to study the dynamics of the heat storages in the soil. The turbulence complex (2.69 $\mathrm{m}$ above ground) was equipped with a sonic anemometer (CSAT3, Campbell Inc., USA) and a LICOR 7500 gas analyzer (LICOR, USA). The data correction and calculation procedure is described by Mauder and Foken (2004), including a complete quality control and footprint analysis (Foken et al., 2004). Additionally, the radiation sensors (albedometer: CM24, Kipp \& Zonen, Netherlands; double dome pyrgeometer: PIR, Eppley, USA) were compared before the experiment. The soil was equipped with five heat flux plates, a temperature profile with nine levels, and a soil moisture profile with three levels. The soil heat flux at the surface was calculated from a combination of the gradient approach (applied at $20 \mathrm{~cm}$ depth) and calorimetry (change in soil heat storage with time, applied between 0 and $20 \mathrm{~cm}$ depth), which was found by a sensitivity analysis as an optimal approach (Liebethal et al., 2005).

During the measurement period from $19 / 05 / 2003$ to $17 / 06 / 2003$, temperature maxima were above $25^{\circ} \mathrm{C}$ every day. Absolute humidity ranged between 5 and $15 \mathrm{~g} \mathrm{~m}^{-3}$. Typical maxima of both sensible and latent heat flux ranged between $150 \mathrm{Wm}^{-2}$ and $200 \mathrm{Wm}^{-2}$. The average wind velocity was approx. $3 \mathrm{~m} \mathrm{~s}^{-1}$ and $30 \mathrm{~min}$ maxima and at $10 \mathrm{~m}$ height were $11 \mathrm{~m} \mathrm{~s}^{-1}$. The atmospheric stratification expressed by the dimensionless parameter $z / L$, where $z$ is the measurement height of $2.69 \mathrm{~m}$ and $L$ is the Obukhov length, varied between 0.5 during nighttime and -0.5 during daytime.

\section{Investigation of the residual of the energy balance clo- sure}

As mentioned in the brief introduction, the reason for the residual of the energy balance closure is probably less connected with the high frequency part of the turbulence spectra (i and ii) but with the low frequency part (iii). Therefore in this section, based on the usual averaging interval for turbulent fluxes of $30 \mathrm{~min}$, the high and low frequency parts were separately investigated and finally, the low frequency part of the spectra was analysed up to $240 \mathrm{~min}$. This paper only covers the problem of fluxes within a not very large extension of the averaging interval. Longer extensions of the averaging interval, as well as results regarding to the problems I and ii, are discussed in an overview paper about the energy balance closure during LITFASS-2003 (Foken et al., 2006).

\subsection{The low and high frequency part of the turbulence spec- tra}

For this investigation, the turbulent time series were split into parts of frequencies lower and higher than $0.1 \mathrm{~Hz}$ using a wavelet filter (Thomas and Foken, 2005). Low and high-frequency fluxes were determined by means of eddycovariance using the filtered data. The method is energy consistent, because the sum of both fluxes is equal to the flux determined for the $30 \mathrm{~min}$ interval with the eddy-covariance method.

Because a direct comparison of both parts of the turbulent flux with the residual did not show a significant correlation, the temporal dynamics of the fluxes and the residual was investigated. For this purpose both parts of the sensible and latent heat flux and the residual were determined at a temporal resolution of five minutes based on overlapping 30-min 

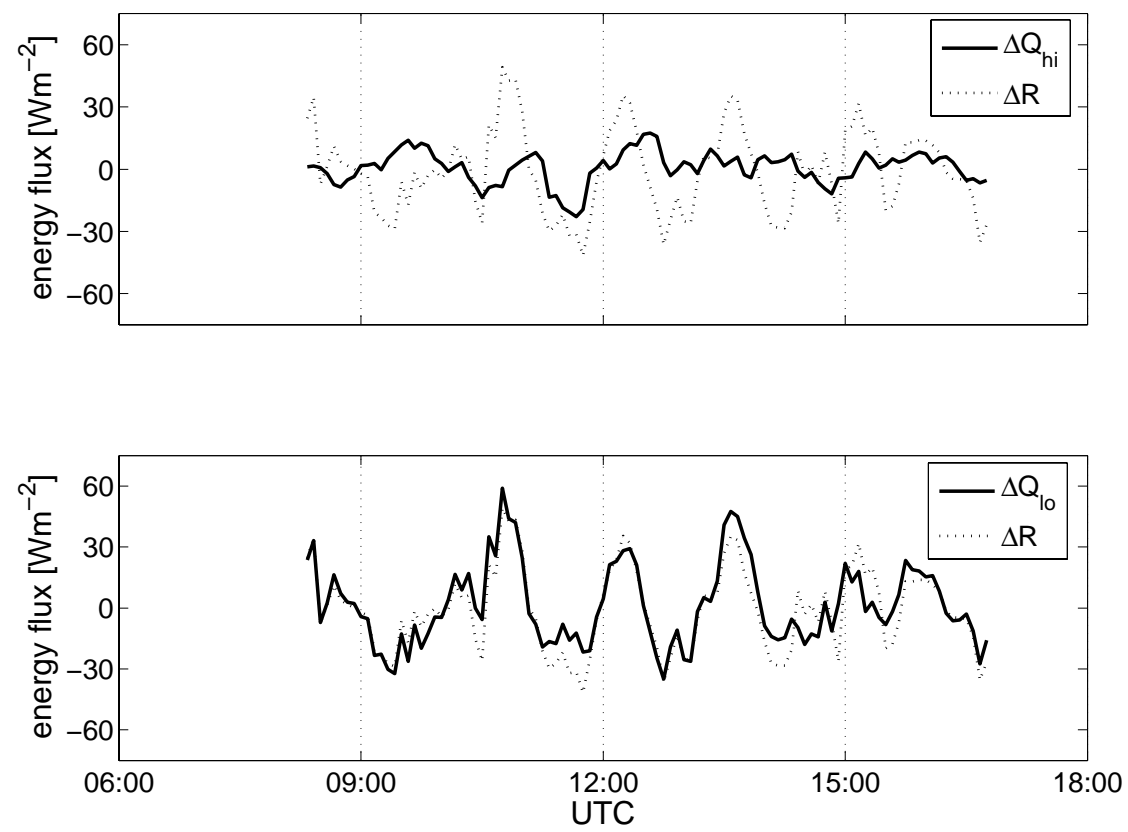

Fig. 1. Comparison of the change of the turbulent fluxes of sensible and latent heat in the high frequency range $\left(\Delta Q_{\text {hi }}\right)$ and the low frequency range $\left(\Delta Q_{\mathrm{lo}}\right)$ and the change of the residual of the energy balance closure $(\Delta R)$ for 30 min averages determined for time steps of 5 min. A moving average (daily cycle) was subtracted (08/06/2003).

intervals. The change of each parameter between two adjacent time stamps was used as a measure of its temporal dynamics. Subsequently, the correlation between the temporal dynamics and the different flux contributions and the temporal dynamics of the residual was analyzed. In order to reduce the number of parameters to be analysed, the high-frequency part of both sensible and latent heat flux were summed up to build the high-frequency turbulent heat flux $Q_{\mathrm{hi}}$. The turbulent flux in the low-frequency range $Q_{\text {lo }}$ was defined analogously. Building such composite fluxes is reasonable because the correlation between the dynamics of the two lowfrequency parts and accordingly the two high-frequency parts is obvious $\left(R^{2}>0.5\right)$, whereas the dynamics of the two parts of the sensible as well as of the latent heat flux are not correlated significantly $\left(R^{2}<0.1\right)$.

No correlations were found between the changes of the turbulent fluxes in the high frequency range $Q_{\mathrm{hi}}$ and the changes of the residual. On the contrary, the changes of the turbulent fluxes in the low frequency range $Q_{\text {lo }}$ and the change of the residual are closely connected (Fig. 1) and were significantly correlated on $07 / 06 / 2003\left(R^{2}=0.85\right)$ and $08 / 06 / 2003$ $\left(R^{2}=0.71\right)$. On $09 / 06 / 2003$ (with changing cumulus cloudiness) no significant correlation was found. A lesser degree of correlation was always associated with steep jumps of the net radiation due to changing cloudiness, because the inertial reaction of the turbulent fluxes leads to a highly variable residual in such situations. Excluding all data with a change in net radiation greater than 2.5 times its standard deviation for all three days, significant correlations $\left(R^{2}=0.85 ; 0.89 ; 0.87\right)$ were found for the low-frequency range, but still not for the high-frequency range.

From these findings it follows that the residual of the energy balance closure is more connected with the low frequency part of the turbulent flux than with the high frequency part. In the following section this low frequency part will be investigated with the suitable ogive test.

\subsection{The ogive test}

Desjardins at al. (1989) and Oncley et al. (1990) introduced the ogive function into the investigation of turbulent fluxes. This function was proposed as a test to check if all low frequency parts are included in the turbulent flux measured with the eddy-covariance method (Foken et al., 1995; Foken et al., 2004). The ogive is the cumulative integral of the cospectrum starting with the highest frequencies

$\operatorname{og}_{w, x}\left(f_{0}\right)=\int_{\infty}^{f_{0}} C o_{w, x}(f) d f$

with $C o_{w, x}$ : co-spectrum of a turbulent flux, $w$ : vertical wind component, $x$ : horizontal wind component or scalar, $f$ : frequency. In this study, co-spectra for all interesting combinations of time series were calculated up to four hours. Though only frequency values higher than approx. $1.3910^{-4} \mathrm{~Hz}$ that correspond to periods of two hours and shorter were used for the test, an underlying interval of four hours improves the statistical significance. Longer periods were not investigated due to the daily cycle of the fluxes and high non-steady 
Table 1. Definition of three different cases for the behaviour of ogive functions.

\begin{tabular}{cll}
\hline Case & explanation & criterion \\
\hline 1 & convergent ogives within the 30 minute interval & $\frac{|\operatorname{og}(150 \mathrm{~min})|}{\max |\operatorname{og}|}>0.9$ and \\
$\frac{|\log (30 \mathrm{~min})|}{\max |\operatorname{og}|}>0.9$ \\
\hline 2 & $\begin{array}{l}\text { ogives with a distinct extreme value before a } \\
150 \text { min integration time }\end{array}$ & $\frac{|\operatorname{og}(150 \mathrm{~min})|}{\max |\log |} \leq 0.9$ \\
\hline 3 & ogive not convergent even for 150 min & $\frac{|\log (30 \mathrm{~min})|}{\max |\log |} \leq 0.9$ and \\
& & $\frac{|\log (150 \mathrm{~min})|}{\max |\operatorname{og}|}>0.9$ \\
\hline
\end{tabular}

state conditions. Because the ogive test must be done with the original not gap-filled time series special tests must be done: The ogive test fails if missing values are in the time series. It was found that even for 288000 data points $(4 \mathrm{~h})$ only intervals without any missing values can be accepted in order to avoid that any ogives based on defective co-spectra are marked as reliable by an automated selection scheme. However, a number of ogives that look quite realistic are discarded due to this rigorous criterion. Furthermore, the time shift of the vertical wind and the horizontal wind or scalar in the original data must be below $0.5 \mathrm{~s}$ and has to be corrected. The number of acceptable data sets was different for the momentum, sensible and latent heat flux. To compare the data, only data sets acceptable for all three fluxes were analyzed. Therefore the number was reduced to 17 for the Golden Days and 121 for the whole experiment. The convergence of the ogive was analysed as follows:

In the ideal convergent case, the ogive function increases during the integration from high frequencies to low frequencies until a certain value is reached and remains on a more or less constant plateau before a $30 \mathrm{~min}$ integration time. If this condition is fulfilled, the $30 \mathrm{~min}$ covariance is a reliable estimate for the turbulent flux, because we can assume that the whole turbulent spectrum is covered within that interval and that there are only negligible flux contributions from longer wavelengths (Case 1). Because of the variability of spectra we tolerate deviations of $10 \%$ for the plateau value when defining Case 1 (Table 1). Figure 2a can serve as an example for this case. But it can also occur that the ogive function shows an extreme value and decreases again afterwards (Case 2, Fig. 2b) or that the ogive function doesn't show a plateau but increases throughout (Case 3, Fig. 2c). Ogive functions corresponding to Case 2 or 3 indicate that a $30 \mathrm{~min}$ flux estimate is possibly inadequate.

An overview of the number of measuring series compliant with these cases is given in Table 2 for all three days and the whole experiment. Note that adjacent four hour time series upon which the ogives are based overlap for two hours in order to attain higher temporal resolution. On 09/06/2003, all acceptable ogives are convergent (Case 1) and most of the time a convergent ogive function was already reached after five minutes for all fluxes. On 07 and 08/06/2003, the ogives for the latent heat flux are more often convergent than the ogives of the sensible heat flux. There is a trend that ogives with a maximum for shorter integration intervals (Case 2) occur on $07 / 06 / 2003$. Typical differences in the frequency of the cases in the morning and afternoon hours could not be found within the small data set used.

From these findings, it follows that the eddy-covariance method does not measure the total flux within the $30 \mathrm{~min}$ interval in all cases. The 30 min flux may be reduced because the total flux was already reached in a shorter time period (Case 2) and an integration of up to 30 min reduces the fluxes due to non-steady state conditions or longwave trends, or because significant flux contribution can be found for integration periods larger than $30 \mathrm{~min}$ (Case 3).

To underline this finding, the relative residual (residual normalised by the available energy)

$$
\frac{R e s}{R_{n}-G}
$$

was compared with value of the ogive at 120 min integration time divided by the ogive value with an integration time of 30 min:

$$
R_{o g}=\frac{o g_{120 \mathrm{~min}}}{o g_{30 \mathrm{~min}}}
$$

This is illustrated in Fig. 3. For $R_{o g} \sim 1$, the ogives converge within the $30 \mathrm{~min}$ time interval (Case 1). In the case of a good convergence of the ogives $\left(R_{o g}=1\right)$, all values of the relative residual are possible, including the case that the relative residual less than 0.1 (the energy balance equation is fully closed). For $R_{o g}>1$ the ogives converge for longer time intervals than 30 minutes (Case 3 ) and for $R_{o g}<1$ they have a maximum (Case 2), in most cases for time intervals lower than $30 \mathrm{~min}$. In Fig. 3, for high relative residuals the scatter of $R_{o g}$ is quite high, while low relative residuals correspond with $R_{o g} \approx 1$. A triangle-like structure with the top pointing downwards can be seen in every subplot. The bottom border 


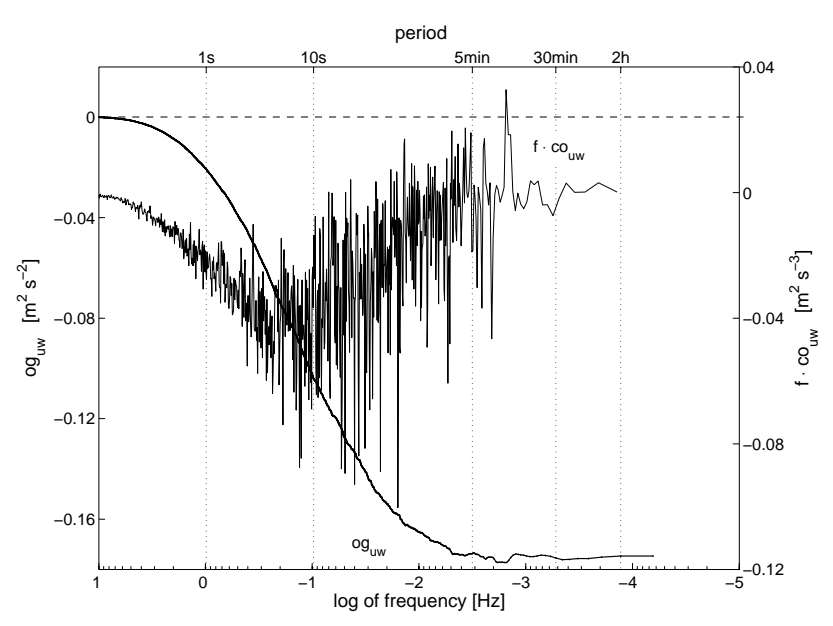

Fig. 2a. Ogiven (og) convergent within 30 minutes (Case 1) and cospectrum (co), momentum flux on 09/06/2003 (12:30-16:30 UTC).

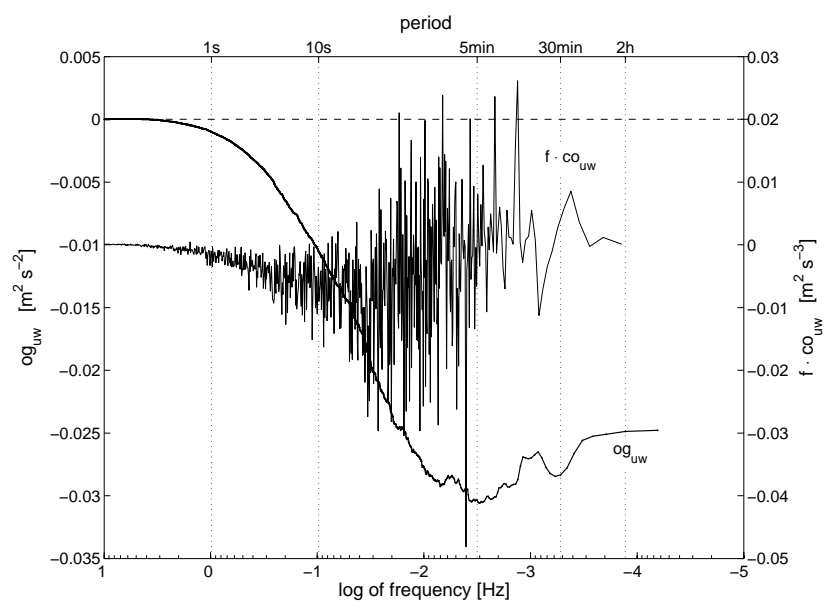

Fig. 2b. Ogive $(o g)$ with a distinct maximal value (extreme) and a decline for longer integration periods (Case 2) and co-spectrum (co), momentum flux on 07/06/2003 (10:30-14:30 UTC).

of the triangle could be taken as a possible minimum value of the relative residual at a certain value of $R_{o g}$. Obviously, $R_{o g} \approx 1$ is a constraint for a possible minimum value of the relative residual.

It must be assumed that a reduction of the turbulent fluxes also occurs if the ogive function has an extreme value for time periods lower than $30 \mathrm{~min}$ and decreases for longer integration times (Case 2). This case occurs only in the transition time with non steady state conditions or in periods with low fluxes. This can be seen from the comparison of the values of the ogive function in Figs. 2a and b. Therefore, this case is not very easy to investigate, because of its infrequent occurrence. It seems, especially for the sensible heat flux, that different eddy sizes have different signs of the flux as well.

Furthermore, the flux is underestimated in the 30 min integration time if energy is also transported with low frequency eddies (Case 3). Reasons for that are non-steady state con-

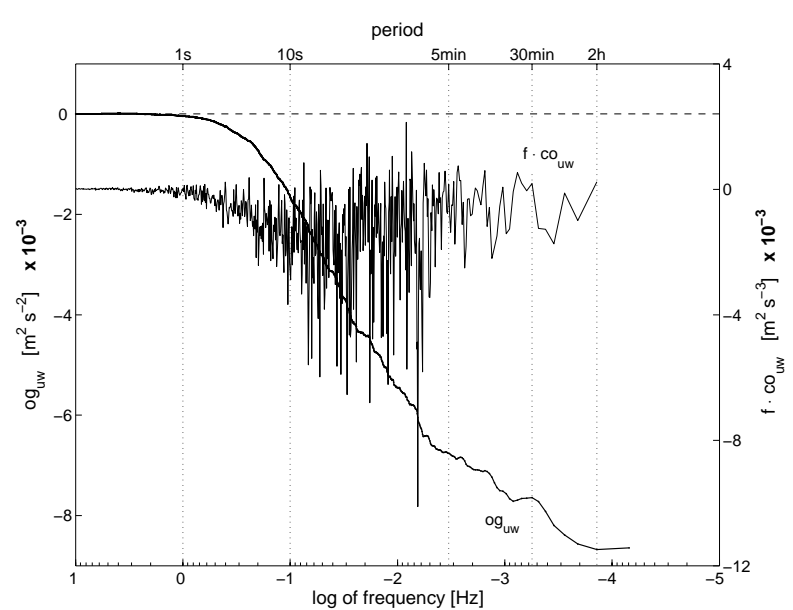

Fig. 2c. Ogive $(o g)$ not convergent within 30 minutes (Case $3)$ and co-spectrum ( $c o$ ), momentum flux on 08/06/2003 (02:30 06:30 UTC).

Table 2. Number of convergent ogives (Case 1), ogives with an extreme value (Case 2), non-convergent ogives (Case 3) for the three investigated days of the ogives of fluxes of momentum $\left(\operatorname{og}_{u w}\right)$, sensible heat $\left(\operatorname{og}_{w T}\right)$, latent heat $\left(\operatorname{og}_{w a}\right)$. The data were selected according to the data quality given in the text. The numbers in brackets are for the whole period from 22/05/2003 to 17/06/2003 with the percentages of the data set of 121 series.

\begin{tabular}{cccc}
\hline & Case 1 & Case 2 & Case 3 \\
\hline $\operatorname{og}_{u w}$ & $14(103,85 \%)$ & $2(13,11 \%)$ & $1(5,4 \%)$ \\
$\operatorname{og}_{w T}$ & $14(100,83 \%)$ & $2(14,12 \%)$ & $1(7,6 \%)$ \\
$\operatorname{og}_{w a}$ & $16(100,83 \%)$ & $1(17,14 \%)$ & $0(4,3 \%)$ \\
\hline
\end{tabular}

ditions and trends, which either cannot entirely or at least not sufficiently be found with the relevant tests (Foken and Wichura, 1996; Vickers and Mahrt, 1997), or advective conditions. These findings explain the fact that turbulent fluxes are always underestimated. A simplified correction of the turbulent fluxes by the ratio of the ogive function for $30 \mathrm{~min}$ and the maximum ogive function (extreme or convergence) shows a reduced residual (Fig. 4). Because the change of the flux is not very large and relevant only for approx. $80-85 \%$ of the data both parts of Fig. 4 (uncorrected and corrected) are not very different. More interesting is the visible result, that the correction has a different influence at different days, mainly for $07 / 06 / 2003$ and nearly not at all for $09 / 06 / 2003$. Therefore, the hypothesis given above about the forcing of the fluxes should be a subject of further investigations.

\section{Conclusions}

From the findings of this study and from many papers it can be assumed that turbulent fluxes in the high frequency 

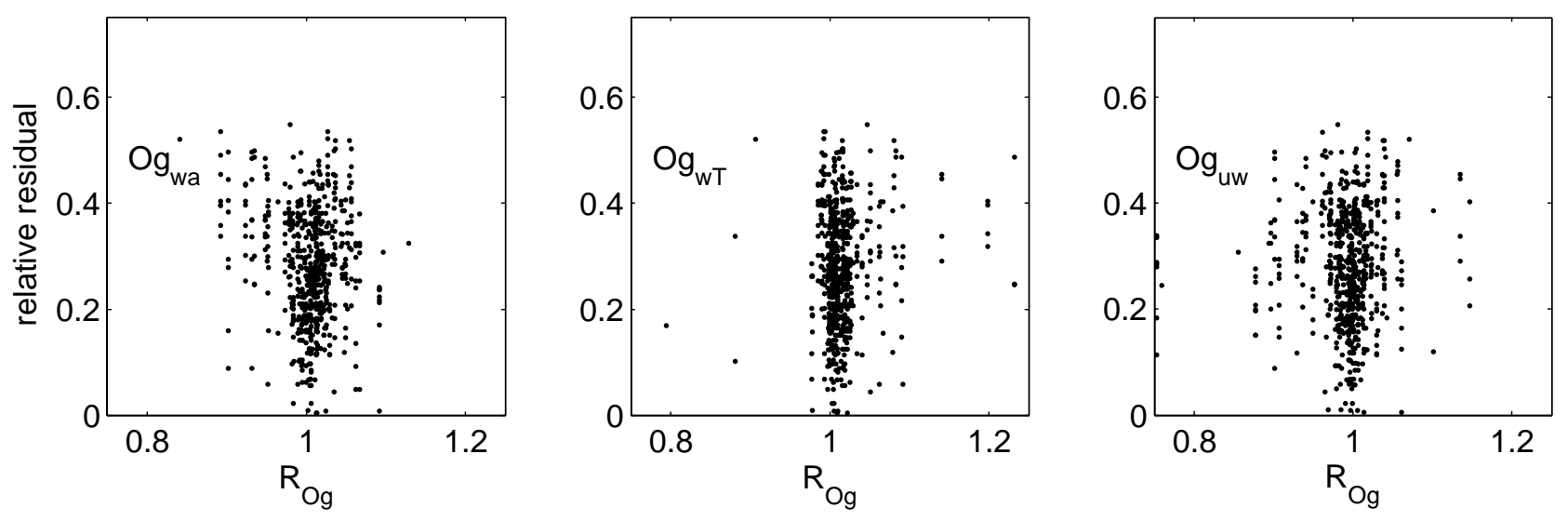

Fig. 3. Relative residual (residual normalised with the available energy) dependent on the ratio $R_{\text {og }}=\operatorname{og}(120 \mathrm{~min}) / \mathrm{og}(30 \mathrm{~min})$ for the sensible and latent heat flux, and the momentum flux.
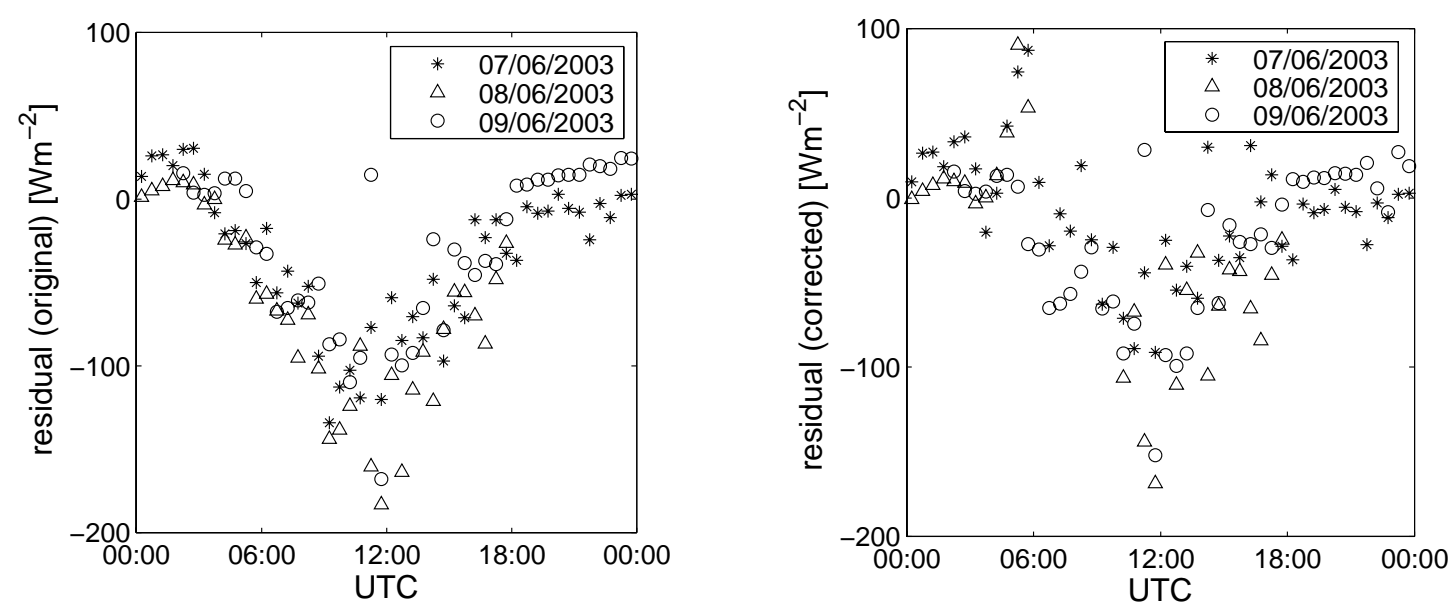

Fig. 4. Residual of the energy balance closure for 30 min averages: on the left side are the calculations with high quality radiation and flux data, and on the right side these calculations are corrected for turbulent fluxes by the ratio max $\mid$ og $\mid \operatorname{og}$ (30 min).

range of the turbulent spectra can be measured exactly with the eddy-covariance method. All necessary corrections of the high frequency part of the spectra are, according to our present knowledge, well done and cannot explain the residual of the energy balance closure (i). In addition, time shifts between different fluxes due to storage influences cannot explain the residual for $30 \mathrm{~min}$ means (ii).

Therefore, the main reasons for the unclosed energy balance are influences on the low frequency part of the turbulence spectra (iii) caused by the landscape of the area where the flux measuring site is situated, as already assumed by Finnigan et al. (2003). A possible explanation can be organized turbulent structures (Kanda et al., 2004) or secondary circulations (Inagaki et al., 2006). The turbulent fluxes in the low frequency part of the spectra can influence the flux in two ways and can partly explain the residual of the energy balance closure. One reason, already discussed by Finnigan et al. (2003), are fluxes missing because of a convergence of the ogive function for integration times larger than $30 \mathrm{~min}$
(Case 3). The reduction of the turbulent fluxes in situations when the ogive function has an extreme value for time periods lower than 30 min may also be caused by fluxes in the low frequency part with the opposite sign (Case 2). The ogive function can be helpful to investigate such situations and also to partly correct the energy loss. But the effect of a correction of the fluxes using an ogive function can only explain the energy balance problem by $5-10 \%$ (Foken et al., 2006), which can be seen from Fig. 4.

It is also interesting that on 09/06/2003 the residual of the energy balance closure has its lowest values and the ogive function is often convergent after only five minutes (Fig. 4). The day is characterised by the highest wind velocities of up to $7 \mathrm{~m} \mathrm{~s}^{-1}$ and a quickly changing irradiation due to cumulus clouds. This may indicate a forcing of the turbulent exchange in time periods of about five minutes. On the other hand, the day with the lowest wind velocities $(07 / 06 / 2003)$ also has a reduced residual. This agrees with findings by Jegede et al. (2004) describing an experiment in the tropics 
with a strong radiation forcing, where the energy balance was closed in most of the cases. For this experiment, the same data calculation software was used as for LITFASS-2003. Obviously under cases with a strong radiation forcing or with a highly variable radiation and velocity forcing with time periods shorter than $30 \mathrm{~min}$ the influence of the landscape and larger turbulent structures discussed above is reduced.

All turbulent fluxes do not have for all conditions a similar convergence of the ogives (Table 2). While a similarity of scalars was found for the high frequency spectra (Pearson Jr. et al., 1998), typical differences were found in the low frequency part (Ruppert et al., 2006), probably connected with the sink/source functions of the scalars, which can be different during the daily cycle. Therefore, the residual of the energy balance cannot be used for the correction of other turbulent fluxes like the carbon dioxide flux and other trace gas fluxes. Each flux must be analysed separately.

Summarising these results, the eddy-covariance method should be used in some cases with a variable integration period, where the length of this period can be determined by the maximum of the ogive function. This implies that the influence of the advection and low frequency turbulence structures can be partially estimated. This paper can only be a first initiative to investigate more carefully the low frequency part of the turbulent fluxes in relation to the energy balance closure problem. Much more data sets under different conditions must be analysed in a similar way to investigate this hypothesis and to create new findings for the use of the eddy-covariance method. It must also be mentioned that many correction methods for the eddycovariance method are based on the high frequency part of the turbulence spectra and cannot simply be transferred for longer integration intervals.

Edited by: A. B. Guenther

\section{References}

Aubinet, M., Grelle, A., Ibrom, A., Rannik, Ü., Moncrieff, J., Foken, T., Kowalski, A. S., Martin, P. H., Berbigier, P., Bernhofer, C., Clement, R., Elbers, J., Granier, A., Grünwald, T., Morgenstern, K., Pilegaard, K., Rebmann, C., Snijders, W., Valentini, R., and Vesala, T.: Estimates of the annual net carbon and water exchange of forests: The EUROFLUX methodology, Adv. Ecol. Res., 30, 113-175, 2000.

Beyrich, F., Herzog, H.-J., and Neisser, J.: The LITFASS project of DWD and the LITFASS-98 Experiment: The project strategy and the experimental setup, Theor. Appl. Climat., 73, 3-18, 2002a.

Beyrich, F., Richter, S. H., Weisensee, U., Kohsiek, W., Lohse, H., DeBruin, H. A. R., Foken, T., Göckede, M., Berger, F. H., Vogt, R., and Batchvarova, E.: Experimental determination of turbulent fluxes over the heterogeneous LITFASS area: Selected results from the LITFASS-98 experiment, Theor. Appl. Climat., 73, 19-34, 2002b.

Bolle, H.-J., André, J.-C., Arrie, J. L., Barth, H. K., Bessemoulin, P., A., B., DeBruin, H. A. R., Cruces, J., Dugdale, G., Engman, E. T., Evans, D. L., Fantechi, R., Fiedler, F., Van de Griend, A.,
Imeson, A. C., Jochum, A., Kabat, P., Kratsch, P., Lagouarde, J.P., Langer, I., Llamas, R., Lopes-Baeza, E., Melia Muralles, J., Muniosguren, L. S., Nerry, F., Noilhan, J., Oliver, H. R., Roth, R., Saatchi, S. S., Sanchez Diaz, J., De Santa Olalla, M., Shutleworth, W. J., Sogaard, H., Stricker, H., Thornes, J., Vauclin, M., and Wickland, D.: EFEDA: European field experiment in a desertification-threatened area, Ann. Geophys., 11, 173-189, 1993 ,

http://www.ann-geophys.net/11/173/1993/.

Culf, A. D., Foken, T., and Gash, J. H. C.: The energy balance closure problem, in: Vegetation, water, humans and the climate. A new perspective on an interactive system, edited by: Kabat, P., Claussen, M., Dirmeyer, P. A., et al., Springer, Berlin, Heidelberg, 159-166, 2004.

Desjardins, R. L., MacPherson, J. I., Schuepp, P. H., and Karanja, F.: An evaluation of aircraft flux measurements of $\mathrm{CO}_{2}$, water vapor and sensible heat., Boundary-Layer Meteorol., 47, 55-69, 1989.

Finnigan, J. J., Clement, R., Malhi, Y., Leuning, R., and Cleugh, H. A.: A re-evaluation of long-term flux measurement techniques, Part I: Averaging and coordinate rotation, Boundary-Layer Meteorol., 107, 1-48, 2003.

Foken, T., Dlugi, R., and Kramm, G.: On the determination of dry deposition and emission of gaseous compounds at the biosphereatmosphere interface, Meteorol. Z., 4, 91-118, 1995.

Foken, T., Göckede, M., Mauder, M., Mahrt, L., Amiro, B. D., and Munger, J. W.: Post-field data quality control, in: Handbook of Micrometeorology: A Guide for Surface Flux Measurement and Analysis, edited by: Lee, X., Massman, W. J., and Law, B., Kluwer, Dordrecht, 181-208, 2004.

Foken, T., Mauder, M., Liebethal, C., Wimmer, F., Beyrich, F., Raasch, S., DeBruin, H. A. R., Meijninger, W. M. L., and Bange, J.: Attempt to close the energy balance for the LITFASS-2003 experiment, 27th Conference on Agricultural and Forest Meteorology, American Meteorological Society, San Diego, paper 1.11, 2006.

Foken, T. and Oncley, S. P.: Results of the workshop "Instrumental and methodical problems of land surface flux measurements", Bull. Am. Meteorol. Soc., 76, 1191-1193, 1995.

Foken, T. and Wichura, B.: Tools for quality assessment of surfacebased flux measurements, Agric. Forest. Meteorol., 78, 83-105, 1996.

Foken, T., Wichura, B., Klemm, O., Gerchau, J., Winterhalter, M., and Weidinger, T.: Micrometeorological conditions during the total solar eclipse of August 11, 1999, Meteorol. Z., 10, 171178, 2001.

Inagaki, A., Letzel, M. O., Raasch, S., and Kanda, M.: Impact of surface heterogeneity on energy imbalance: A study using LES, J. Meteorol. Soc. Japan, 84, 187-198, 2006.

Jegede, O. O., Mauder, M., Okogbue, E. C., Foken, T., Balogun, E. E., Adedokun, J. A., Oladiran, E. O., Omotosho, J. A., Balogun, A. A., Oladosu, O. R., Sunmonu, L. A., Ayoola, M. A., Agregbesola, T. O., Ogolo, E. O., Nymphas, E. F., Adeniyi, M. O., Olatona, G. I., Ladipo, K. O., Ohamobi, S. I., Gbobaniyi, E. O., and Akinlade, G. O.: The Nigerian micrometeorological experiment (NIMEX-1): An overview, IFE J. Sci., 6, 191-202, 2004.

Kanda, M., Inagaki, A., Letzel, M. O., Raasch, S., and Watanabe, T.: LES study of the energy imbalance problem with eddy covari- 
ance fluxes, Boundary-Layer Meteorol., 110, 381-404, 2004.

Kanemasu, E. T., Verma, S. B., Smith, E. A., Fritschen, L. Y., Wesely, M., Fild, R. T., Kustas, W. P., Weaver, H., Steawart, Y. B., Geney, R., Panin, G. N., and Moncrieff, J. B.: Surface flux measurements in FIFE: An overview, J. Geophys. Res., 97, 18 547$18555,1992$.

Kukharets, V. P., Nalbandyan, H. G., and Foken, T.: Thermal Interactions between the underlying surface and a nonstationary radiation flux, Izv., Atmos. \& Ocenanic Phys., 36, 318-325, 2000.

Liebethal, C., Huwe, B., and Foken, T.: Sensitivity analysis for two ground heat flux calculation approaches, Agric. Forest. Meteorol., 132, 253-262, 2005.

Mauder, M. and Foken, T.: Documentation and instruction manual of the eddy covariance software package TK2, Abt. Mikrometeorologie, Arbeitsergebnisse, 26, Print: ISSN 1614-8916, 42 pp, 2004.

Mauder, M., Liebethal, C., Göckede, M., Leps, J.-P., Beyrich, F., and Foken, T.: Processing and quality control of eddy covariance data during LITFASS-2003, Boundary-Layer Meteorol., online, doi:10.1007/s10546-006-9094-0, 2006.

Mengelkamp, H.-T., Beyrich, F., Heinemann, G., Ament, F., Bange, J., Berger, F.H., Bösenberg, J., Foken, T., Hennemuth, B., Heret, C., Huneke, S., Johnsen, K.-P., Kerschgens, M., Kohsiek, W., Leps, J.-P., Liebethal, C., Lohse, H., Mauder, M., Meijninger, W. M. L., Raasch, S., Simmer, C., Spieß, T., Tittebrand, A., Uhlenbrook, S., and Zittel, P.: Evaporation over a heterogeneous land surface: The EVA_GRIPS project, Bull. Am. Meteorol. Soc., 87, 775-786, 2006.

Moncrieff, J.: Surface turbulent fluxes, in: Vegetation, water, humans and the climate. A new perspective on an interactive system, edited by: Kabat, P., Claussen, M., Dirmeyer, P. A., et al., Springer, Berlin, Heidelberg, 173-182, 2004.
Oncley, S. P., Businger, J. A., Itsweire, E. C., Friehe, C. A., LaRue, J. C., and Chang, S. S.: Surface layer profiles and turbulence measurements over uniform land under near-neutral conditions, 9th Symp. on Boundary Layer and Turbulence, Am. Meteorol. Soc., Roskilde, Denmark, 237-240, 1990.

Panin, G. N., Tetzlaff, G., and Raabe, A.: Inhomogeneity of the land surface and problems in the parameterization of surface fluxes in natural conditions, Theor. Appl. Climat., 60, 163-178, 1998.

Pearson Jr., R. J., Oncley, S. P., and Delany, A. C.: A scalar similarity study based on surface layer ozone measurements over cotton during the California Ozone Deposition Experiment, J. Geophys. Res., 103(D15), 18919-18926, 1998.

Ruppert, J., Thomas, C., and Foken, T.: Scalar similarity for relaxed eddy accumulation methods, Boundary-Layer Meteorol., 120, 39-63, 2006.

Sakai, R. K., Fitzjarrald, D. R., and Moore, K. E.: Importance of low-frequency contributions to eddy fluxes observed over rough surfaces, J. Appl. Meteorol. 40, 2178-2192, 2001.

Thomas, C. and Foken, T.: Detection of long-term coherent exchange over spruce forest, Theor. Appl. Climatol., 80, 91-104, 2005.

Tsvang, L. R., Fedorov, M. M., Kader, B. A., Zubkovskii, S. L., Foken, T., Richter, S. H., and Zelený, J.: Turbulent exchange over a surface with chessboard-type inhomogeneities, BoundaryLayer Meteorol., 55, 141-160, 1991.

Vickers, D. and Mahrt, L.: Quality control and flux sampling problems for tower and aircraft data, J. Atm. Oceanic Techn., 14, 512-526, 1997.

Wilson, K. B., Goldstein, A. H., Falge, E., Aubinet, M., Baldocchi, D., Berbigier, P., Bernhofer, C., Ceulemans, R., Dolman, H., Field, C., Grelle, A., Law, B., Meyers, T., Moncrieff, J., Monson, R., Oechel, W., Tenhunen, J., Valentini, R., and Verma, S.: Energy balance closure at FLUXNET sites, Agric. Forest. Meteorol., 113, 22300234, 2002. 